Rochester Institute of Technology

RIT Scholar Works

Articles

Faculty \& Staff Scholarship

Fall 10-2020

\title{
Minecrafting Bar Mitzvah: Two Rabbis Negotiating and Cultivating Learner-Driven Inclusion through New Media.
}

Owen Gottlieb

Rochester Institute of Technology

Follow this and additional works at: https://scholarworks.rit.edu/article

Part of the Art Education Commons, Curriculum and Instruction Commons, Digital Humanities Commons, Educational Leadership Commons, Educational Methods Commons, Educational Technology Commons, Ethics in Religion Commons, Ethnic Studies Commons, Game Design Commons, Instructional Media Design Commons, Interactive Arts Commons, Interdisciplinary Arts and Media Commons, Jewish Studies Commons, Language and Literacy Education Commons, Other Arts and Humanities Commons, Other Film and Media Studies Commons, Practical Theology Commons, Religious Education Commons, Religious Thought, Theology and Philosophy of Religion Commons, Social Justice Commons, Special Education and Teaching Commons, and the Teacher Education and Professional Development Commons

\section{Recommended Citation}

Gottlieb, Owen (2020). Minecrafting Bar Mitzvah: Two Rabbis Negotiating and Cultivating Learner-Driven Inclusion through New Media. In The Journal of Religion, Media, and Digital Culture: Vol. 9 Issue 2 (pp. 185-206). Brill Publishing.

This Article is brought to you for free and open access by the Faculty \& Staff Scholarship at RIT Scholar Works. It has been accepted for inclusion in Articles by an authorized administrator of RIT Scholar Works. For more information, please contact ritscholarworks@rit.edu. 
Appears in:

Gottlieb, Owen (2020). Minecrafting Bar Mitzvah: Two Rabbis Negotiating and Cultivating Learner-Driven Inclusion through New Media. In The Journal of Religion, Media, and Digital Culture: Vol. 9 Issue 2 (pp. 185-206). Brill Publishing.

\title{
Author Manuscript:
}

Minecrafting Bar Mitzvah: Two Rabbis Negotiating and Cultivating Learner-Driven Inclusion through New Media

\section{Owen Gottlieb}

School of Interactive Games and Media Golisano College of Computing and Information Sciences

and

Initiative in Religion, Culture, and Policy, MAGIC Center

Rochester Institute of Technology

Keywords

video games - ritual - Judaism - differentiated instruction - inclusion - accessibility - narrative - Jewish Education

\begin{abstract}
In 2013, a boy with special needs used the video game Minecraft to deliver the sermon at his bar mitzvah at a Reform synagogue, an apparently unique ritual phenomenon to this day. Using a narrative inquiry approach, this article examines two rabbis' negotiations with new media, leading up to, during, and upon reflection after the event. The article explores acceptance, innovation, and validation of new media in religious practice, drawing on Campbell's (2010) framework for negotiation of new media in religious communities. Clergy biography, philosophy, and institutional context all impact the negotiations with new media. By providing context of a set of factors influencing a particular negotiation and validation of a ritual and educational innovation using new media, the article intends to demonstrate the importance of clergy narrative for understanding new media negotiations in religious settings, and in particular in progressive religious communities.
\end{abstract}


For progressive religious communities these same media may symbolize the opportunity to solidify or strengthen their communities' identity or calling for public proclamation. Therefore the key question is not just how religious users negotiate with new media, but what the ideological basis for their response to new forms of media is in light of their religious community affiliation and unique beliefs (Campbell, 2010, p 132).

Drawing from Campbell's call for an understanding of the ideological basis for negotiation responses to new media, this article uses a narrative inquiry to examine two Reform rabbis' understandings of the incorporation and use of the video game Minecraft (Mojang, 2011) in the preparation for and ceremony of a bar mitzvah of a boy on the autism/Aspergers spectrum. This incorporation of a video game into sanctuary ritual seems to be a unique phenomenon in Reform synagogues to this day. I will show the processes of negotiation with Minecraft in these two rabbis' narratives and provide context regarding how this negotiation with media is situated within both historical and contemporary concerns in differentiated instruction in Reform Judaism. More specifically, I will situate the negotiation within Reform Judaism's longstanding goal of broadening inclusion, including growth in recent years in recognizing inclusion and accessibility as a foregrounded value. While there has been substantive research on Orthodox negotiations with new media (such as the work of Oren Golan and work featured in Campbell's Digital Judaism (2015)), little work has been conducted on non-Orthodox Jewish negotiations with new media. I have written on Reform communities (Gottlieb, 2015a; Gottlieb, 2015b), though I have not found other scholarship on new media and progressive Judaism. This may be due to the perception that new media are not negotiated in Reform Judaism, which typically does not ban electronic devices on Shabbat (the Jewish Sabbath), yet it ignores the boundaries well 
established and constantly negotiated. Such negotiation can be seen in the incorporation of "visual tefilah" projected on screen (Gottlieb, 2013) and the banning of mobile phones at Reform summer camps.

This study is intended to help illuminate the negotiations with video games in religious ritual and learning in a particular context. Here I draw a sharp distinction between the religious ritual in the synagogue sanctuary, on the bimah (raised platform) in the presence of the Torah scroll or the ark in which it is housed, as distinct from themes for parties outside of the sanctuary following the religious ritual. Party themes using Minecraft appear common as evidenced by the Pinterest page "Minecraft Bar Mitzvah-73 Pins, 2,663 followers, ideas and plans for a Minecraft themed bar mitzvah (Bellwether Events and Deb Lindsey, n.d.)" and "WYATT'S MINECRAFT BAR MITZVAH PARTY (Bellwether Events, 2014)." It is the incorporation of the video game into the religious ceremony that makes this phenomenon distinct.

Just as with case studies, through which a qualitative approach with an "n of 1" (Merriam, 1995) can provide insight into phenomena, so too can analysis of narrative provide for insight through allowing closer examination of a specific occurrence or set of occurrences. Through providing this context, I wish to surface specific axes of analysis that scholars of religion and media may consider in the future when parsing negotiations with any number of new media. These factors are, specifically, the biography, lexicon, and pedagogical philosophy of the clergy member(s) or religious educators; the accessibility needs of the congregants or family; the level of differentiation in instruction; and the position of the movements or supporting institutional structures regarding both differentiation and accessibility. 
Methods

This article is organized around a specific ritual event - a 2013 bar mitzvah in which the young man on the Autism spectrum used Minecraft as the organizing principle, giving his sermon through a presentation of a Minecraft space that he had created. The article centers on the stories told, as oral histories, by the two rabbis who organized and co-led the lifecycle ritual. ${ }^{1}$ The reason for this approach is twofold. First, while the ritual was a public event, the family did not respond to queries requesting interviews, while the clergy did offer their perspectives and insights. The opportunity for inquiry was limited. The second reason is that the clergy perspective and point of view are often written out of discussions of the negotiation of new media. This is even the case when clergy are positioned in the community to be the primary translators and interpreters of new media.

For a closer consideration of narrative inquiry, I turn to Creswell (2007). Creswell draws upon a number of scholars, including Donald Polkinghorne, Susan Chase, and Barbara Czarniawska, in order to describe narrative inquiry, study, or method:

Any text or discourse, or, it might be text used within the context of a mode of inquiry in qualitative research... with a specific focus on the stories told by individuals... As a method, it begins with the experiences as expressed in the lived and told stories of individuals... [narrative method] is a specific type of qualitative design in which "narrative is understood as a spoken or written text giving an account of an event/action or series of events/actions,

${ }^{1}$ The Rochester Institute of Technology Human Subjects Research Office (IRB) classified the interviews with the rabbis about a public event as Oral Histories and therefore not Human Subjects Research. 
chronologically connected" (Czarniawska, 2004, p 17.). The procedures for implementing this research consist of focusing on studying one or two individuals, gathering data through the collection of their stories, reporting individual experience, and chronologically ordering (or using life course stages) the meaning of those experiences.... Although narrative research originated from literature, history, anthropology, sociology, sociolinguistics, and education, different fields of study have adopted their own approaches. (Creswell, 2007, p. 54)

Procedurally, Creswell adopts the approach of Clandinin and Connelly (2000). Roughly, the procedural approach is to determine if narrative is the best approach-typically when capturing detailed stories or life experiences of a single person or small number-then to spend time gathering stories and relevant documents, then contextualizing the stories, such as giving historical context. Next, the narrative research analyzes and "restorys" the texts into a new framework in which the stories and the themes that emerge are data. The fifth procedure is collaborating with the participants by actively involving them in the research. Additionally, Creswell turns to Czarniawska (2004) for a postmodern turn in narrative research, pointing out the importance of "exposing dichotomies, examining silences, and attending to disruptions and contractions" (Creswell, 2007, p. 56).

The narratives surrounding the phenomenon I refer to as "the Minecraft Bar Mitzvah" are from a senior and assistant rabbi at a congregation in the northeast United States. I use pseudonyms for the rabbis I interviewed in order to allow for privacy for the family as they elected to not participate in interviews for this article. I also use a pseudonym for the boy who became bar mitzvah. Because the event was public, the rabbis are free to discuss it, as they are 
free to discuss their own perspectives and choices regarding the ritual, as well as the rabbinical perspectives before, during, and in reflection following the event.

And so, I use narrative analysis of the two rabbis' accounts to demonstrate the context otherwise erased from the event regarding conscious negotiations with new media in a Reform synagogue in the United States.

Researcher Stance

There is a third rabbi in the picture - the author. In addition to being a scholar of games, interactive media, and learning, I am a Reform rabbi. In the summer of 2015, I travelled to New York City for a conference on Jewish education held at the campus of the Hebrew Union College-Jewish Institute of Religion. Rabbi Shapiro (a pseudonym ${ }^{2}$ ), a colleague with whom I attended seminary years earlier, approached me. He reminded me that over a year earlier, he had asked me about the possibilities of using Minecraft and video games in Jewish education. I had made suggestions about affordances of Minecraft being best suited to design-based learning projects. In Minecraft, players mine resources from the environment and then build structures. The core mechanics are, as the title suggests, mining and crafting. The game had been popular with children for a number of years already; I had already met children who were devoted to Minecraft while I was teaching part time in supplementary (after school) Hebrew school, and I had attended various talks at games and learning conferences on optimal uses of Minecraft in formal and informal education. My own dissertation research had been in games and learning in

2 The names in this article, other than my own, are pseudonyms. The events described took place between 2013 and 2014, and formal interviews with the rabbis were conducted in 2018 . The boy became bar mitzvah in a Reform congregation in the northeast United States. 
Jewish education contexts, and so I was able to speak to how a game like Minecraft might fit with goals in Jewish education. I suggested that if a learner were to design and build some virtual object or space relevant to the learning objectives of the lesson, it should work.

It was over a year later, and Rabbi Shapiro and I had not communicated since that initial conversation. Shapiro shared that his student, who was on the autism spectrum, had not only studied using Minecraft in a Jewish learning context, but had a very successful "Minecraft Bar Mitzvah" at the synagogue, centered on designing in Minecraft. The student had presented his sermon, or d'var Torah, using a Minecraft walkthrough that the student himself designed and built. Shapiro described the lifecycle event as an important success for the synagogue community. I asked if I could follow up to learn more about the situation and over time learned more about the events that had occurred and about the clergy negotiations with Minecraft in ritual. I conducted interviews with Rabbi Shapiro and his senior rabbi at the time, Rabbi Bernstein, which form the basis for the oral histories recorded for this case. As briefly referred to above in "Methods," I reached out to the family, who declined to participate in the interviews. I use pseudonyms to obscure the identity of the family, though the bar mitzvah itself, while conducted in a smaller more intimate chapel at the synagogue, was open to the wider community. Negotiations of Acceptance, Innovation, Validation

Birgit Meyer (2009) notes that

...one of the reasons why religion remains a vital, appealing force lies exactly in its propensity to transform by incorporating new media and addressing and linking people in new ways. Of course, this transformation does not stand by itself, but occurs within broader processes ( $p$ 2). 
Meyer considers broader processes such as post-colonial nation-states and neoliberal capitalism. The processes that I am interested in exploring are closer to the ritual and educational setting, just one or two strata broader than the ceremonial and educational rituals and processes themselves. These are the contextual frames applied by the clergy regarding how those clergy understand the use of new media (such as the video game Minecraft) in the ritual and educational life of their community, and also how those frames relate to the institutional concerns of a movement, in this case of Reform Jewish expression, and other closely related progressive Jewish communities in early 21 st-century North America.

Campbell (2010) has set out a number of ways in which religious communities negotiate new media, in particular her model of accept, reject, reconfigure, and/or innovate. Campbell also notes that Hoover (1993) understands that negotiations with new media can involve internal and external validation. I consider the Minecraft Bar Mitzvah to be an example of acceptance of new media that is both innovative and also validated at the level of both clergy and broader levels of the institutional understanding. What was the Minecraft Bar Mitzvah, and how did the rabbis understand the medium of the video game in relationship to ritual in synagogue and within their broader understandings of Judaism? In particular, the validation, filtered through the sensibilities of the rabbis, centers on two issues: differentiated learning and inclusion/accessibility. In order to be able to begin unpacking the context of the Minecraft Bar Mitzvah, it is important to understand how the Minecraft aspect of the ritual came about. This ritual includes both the ceremony itself as well as the preparation for the ceremony, a preparation which often involves a year or more of study. The intention of this work is to broaden methods of analysis of religion and media to more fully incorporate analysis of conscious clergy media negotiations and also to 
understand those negotiations in the context of broader concerns of the clergy's peer and institutional groups, in this case, inclusion and accessibility.

The bar mitzvah ceremony marks the first time that a boy (or bat mitzvah for girl) reads or blesses the Torah in public, and historically marks the moment of a child taking on the ritual responsibilities of an adult. Typically, the age of the child at the time of the ceremony is thirteen, with preparation beginning well beforehand. In Reform congregations, the ceremony often involves the bar mitzvah (literally, "son of the commandments") leading a Shabbat (Sabbath) prayer service, giving a d'var Torah (sermon), receiving a blessing from a rabbi, and, in recent decades, sharing a public moment with parents on the bimah-sometimes, in the last two decades, parents read words of pride and praise about their child. Sometimes the bar or bat mitzvah will discuss a community project they worked on. Typically, a family celebration follows the religious ceremony. ${ }^{3}$ How did a bar mitzvah ceremony involving Minecraft come to pass?

\section{Minecraft Bar Mitzvah}

Rabbi Shapiro and his senior colleague Rabbi Bernstein had both spent time with Joel, a young man on the autism spectrum. Joel had an IEP (Individualized Education Protocol). He did not make eye contact and spoke in short rapid sentences. Shapiro describes Joel as bright, quick minded, and if something did not make sense to Joel, "he wasn't having it." Shapiro notes that

3 For a sense of the institutional role and limitations of b'nai mitzvah (plural, gender neutral) in American Jewish learning since the 1930s and 1940s, see Aron's 2010 review and response to the Schoenfeld (1987) essay "Folk Judaism, Elite Judaism, and the Role of Bar Mitzvah in the Development of the Synagogue and Jewish School in America." 
Joel presented challenges for the synagogue because of his unique needs and because the synagogue, at the time, had a "non-unique-needs-friendly system." Joel was "not very religious" and his parents were incentivizing his study through external rewards (in the short term, a favorite food and in the longer term, a new piece of computer or gaming equipment). Joel and his older siblings had completed the minimal amount of training prior to entering the synagogue's bar mitzvah program via presence in the religious school program. For many Hebrew supplementary/complementary schools (after-school educational programs), the b'nai mitzvah (plural, gender neutral for bar and bat mitzvah) programs involve working directly with a rabbi and cantor.

When Rabbi Shapiro had his first bar mitzvah meeting with Joel, he began the conversation by asking about Joel. It is Rabbi Shapiro's practice to make this first meeting a personal chat with the student to get to know him. Rather than discussing anything bar mitzvahrelated in the first meeting, it is, for Rabbi Shapiro, about finding out who the learner is, who the person is with whom he is meeting. In these first meetings, Shapiro also offers to answer questions about himself openly, honestly, and candidly_always in a child-safe way_-but, he specifies, not in an "I'm speaking to a child" style. Shapiro finds this helps in building trust and beginning the process and the teacher-learner relationship.

For Joel, what kept coming up in this conversation was that Joel loved Minecraft, that Minecraft was what Joel really like to do, and everything else in Joel's life, such as school, was understood and organized by Joel as "things he needed to do to play Minecraft."

Because of the way Joel learned and what he had going on for himself clinically, it became quite apparent that doing the traditional bar mitzvah speech, reading Hebrew, doing any of 
that stuff, was not going to happen. And so, I started to try and think of what could happen (Shapiro).

Shapiro decided to pursue offering Joel Minecraft as a means of crafting his bar mitzvah d'var Torah, or sermon, as well as part of his preparatory study.

Shapiro conferred with his senior rabbi, Bernstein. Bernstein was set to be the lead rabbi for the ceremony. Shapiro mentioned my work in games and Jewish learning to Bernstein, and suggested to Bernstein "that we do something off the beaten path and think outside the box/chuck the box in the rubbish and do something completely different." This was when Shapiro had originally briefly touched base with me. Bernstein, seeing Shapiro's sense of possibilities for Joel with Minecraft, encouraged Shapiro to lead on the education side of Joel's preparation - he saw Shapiro had a vision and encouraged it. Shapiro inquired with Joel as to whether Joel could build something related to his Torah portion in Minecraft, to which Joel responded enthusiastically. "Why don't you make your Torah portion?" suggested Shapiro. "Why would I do that?" answered Joel. Shapiro responded,

Well, people are going to come to your bar mitzvah. None of them know what this is about, this is connected to thousands of years of history, and you need to share this with them, or else everybody else will be sitting in a room with no clue why they are there.

This seemed to connect with Joel, and Joel soon was building a visual, three-dimensional representation of aspects of his Torah portion in Minecraft. The family expressed that they did not know such a bar mitzvah could be possible and were surprised and positive.

The eventual ceremony was minimalist - it was held in a chapel, a smaller space than the larger sanctuary, with a small group of family and friends in attendance. The clergy and staff 
built a makeshift screen and set up a projector. Rabbi Shapiro described the service itself as "pretty much like any morning service," though heavily redacted. Joel led a number of prayers. The arc of the service was maintained. Joel did the Shema (a central creed), and he spoke the blessings before and after the Torah reading. He started everyone off on V'ahavta [one of the blessings following the Shema]. Joel stood beside the cantor throughout the service—-the cantor chanted the Torah reading in Hebrew. The presentation of the sermon was Joel and Minecraft. Working from notes, Joel explained to those gathered what Minecraft is, then showed aspects of the Torah portion that he had constructed in Minecraft. Joel's Torah portion was Miketz (Genesis 41:1-44:17), and he reproduced objects and locations from the text in a 3D Minecraft world, including images from Pharaoh's dream, Hebrew letters spelling out the names of Joseph's brothers, a prison, and the goblet that Joseph hid in Benjamin's sack. Joel then described the process of working through the text, making decisions about what he would render. He talked about having hard time identifying with the characters, though he saw Joseph as the author of his own story (just as Joel was designing his own Torah portion in Minecraft.). Joel's father made some remarks and showed that he was emotionally moved by the event. Rabbi Shapiro noted the family's appreciation of the lifecycle event: "I think the fact that we put our heads together and tried to speak Joel's language made the biggest difference for his family." This notion of language, along with Rabbi Shapiro's broader pedagogical approach, can help us understand the negotiation process the clergy is using in this case.

Rabbi Shapiro's Pedagogy: “Geography” and "Language”

When speaking about his own pedagogical approach, both with Joel and with his other students, Rabbi Shapiro refers to what he calls "geography" and "language." In his own terminology, the metaphor of geography refers to his expectation of his need to be in the same 
"place as the learner" and is a precursor to communication. Then, once in that "place," he wants to allow the learner to speak in the learner's "own language." When discussing new media and what they meant to him in this case of working with the learning, Shapiro said,

There's [sic] two pieces. Geography, not in a physical sense, and language. When I'm saying geography, we really did meet that kiddo where he was. And on top of meeting him where he was we reorganized things so that he could speak his own language, and I think particularly with a kid on the spectrum, families rarely have that opportunity-in anything, but especially religion. And it seemed to make the entire event possible for him and it made it meaningful for the family because they weren't plugging into a synagogue, the synagogue was plugging into their kid... They expressed a lot of gratitude... lauding us with praise for taking the effort... talking in ways like, "Well, we didn't really think this was possible, we didn't know what would be happening with this, and what actually happened was not on our radar for this to happen, but we are glad that it did."

Shapiro's use of "geography" is related to a phrase used in Reform Jewish educational and outreach circles as well as experiential learning and " 21 st-century learning" circles-the desire to "meet the learner where they are." Part of the concept is about the importance of engaging learners from a subject matter or modality in which they are already engaged and already have affinity. This can also be seen in outreach in progressive Jewish life which may seek to bring together community members around common hobbies or affinities. But for Shapiro, this extended not just to affinity, but to the connection each learner had to her or his affinities in a deeper sense, linked to core identity—recognizing that what the learner expressed was not just an interest, but rather an organizing principle in life. For Joel, Shapiro said that he perceived that Joel's life was organized around Minecraft. Beyond Joel and Minecraft, for one girl who he said 
her "life was baking" and whose bat mitzvah Torah portion included the commandment to eat matzah, or unleavened bread, Shapiro surprised her by suggesting that she actually bake matzah herself. She did it and brought it to the ceremony, passed it out to the congregation, and gave a sermon about cooking in her family and the passing down of recipes. Shapiro articulates the notion of being "where the learner is at" as "geography" or "place."

The concept of a teacher being in the same "place" as the learner is can be traced back quite far in Judaism, at least as far back as the Babylonian Talmud redacted circa $650 \mathrm{CE}$. The Talmud (Babylonian Talmud, Megillah 21a) cites Deuteronomy 5:28 in which God says to Moses, "And you, stand here with me." Based on this, Rabbi Abahu argues that a teacher should not sit on a couch while students sit on the ground. Similarly, in the 12th century, Maimonides wrote, "The teacher should not sit on a chair, while his students sit on the ground. Rather, either everyone should sit on the ground or everyone should sit on chairs." (Maimonides, Mishneh Torah, Talmud Torah 4:2, Touger translation, 1997). Shapiro, it seems, uses the term "geography" to describe being "where the student is."

On top of meeting him [Joel] where he was, we reorganized things so that he could speak his own language. And I think particularly, with a kid on the spectrum, families rarely have that opportunity in anything, but especially religion, and it seemed to make the entire event possible for him, and it made it meaningful for the family, because they weren't just plugging into a synagogue system, the synagogue system was plugging into their kid.

The second element that Shapiro discusses, once meeting the children "where they are," is the importance of allowing the learners to speak "their own language." Shapiro's use of "language" relates to the way learners act or make in their "place," through experiential learning activities. Learning scientists refer to this kind of learning as constructionism, learning through making, 
building, creating, and designing (Ackerman 2001; Harel \& Papert, 1991; Papert, 1993; Kafai \& Resnick, 2012). I will return to discussion of constructionism below. Shapiro understood Joel's "language" as designing structures in Minecraft and sharing those creations; for the bat mitzvah girl, baking matzah and discussing the importance and meaning of cooking in her life was allowing her to use her "language." So, Shapiro understands the process as going to the "place" around which the learner preferred organizing their lives and then having them build, make, create, and communicate from that place in the learner's "language." What may have influenced Rabbi Shapiro's own take on Rabbi Abahu of the Talmud's mandate?

Clergy Biography Informs Negotiation

Rabbi Shapiro's negotiation and validation of Minecraft is anchored in his biography. One might at first consider clergy-educator biography largely irrelevant to negotiations with new media that such negotiations are driven overwhelmingly by broader institutional concerns and movement mandates. Alternatively, some may argue that at a certain level, whoever is the decision maker is the driver of the negotiation decision and type, and therefore, biography must play into the decisions. This case provides a clear and articulated example of the link between a negotiation of new media in a religious context and the biography of the clergy members. Later in the article, I will provide broader contextualization in the institutional structures of Reform Judaism and progressive Judaism more broadly.

Shapiro grew up on a family farm in the Midwest that he describes as involving: ... a lot of introspection a lot of quiet, careful thought. When I was very small, it was like a children's storybook, but for the vast majority of it was midwestern field crops, corn, soy, occasionally wheat. We had a small herd of sheep and we would sell lambs in the 
springtime and wool twice a year. I don't think we ever had more than 40 or 50 heads of sheep.

Although he holds a master's degree in education, he describes his philosophy of teaching as most importantly, directly related to his own biography:

I really do think that every human being is a gift unto the world, or potentially [a gift], and I view my job as a cultivator, not necessarily a teacher, and having grown up on the farm, if you are really going to cultivate something, you have to help it do what it knows how to do to the best of its ability, whether that's a corn field, or a cow, or a toddler, or whatever [it is]. And I also I think from the farm, I grew up thinking that "I can," because even as a toddler I would go out and help pick lettuce. All you have to do is rip things off of the ground, and toddlers are good at that.

Regarding Minecraft specifically, which Shapiro was largely unfamiliar with before Joel, Shapiro links his interpretation of and openness to Minecraft directly to his own childhood experience:

One of the things that Minecraft reminded me of was Legos, and they were my favorite toy growing up, and they still are, and I still have all of my Legos in the basement. Even the aesthetic, the way things looked in Joel's sermon, reminded me of Legos, and I think that was one of my largest points of creativity growing up, because when I was his age, I was building my universe, but it was out of little plastic bricks from Denmark instead of pixels.

Shapiro continues, discussing Minecraft using terms such as "cultivating" and "fertile ground," even though Minecraft itself has neither cultivation nor fertile ground (only mining). 
I think that malleable creativity where kids can take thought—and let go of boundaries, and use it to create something of themselves - is very fertile ground for innovation, for cultivating innovative thinking, and potentially for teaching a lot about how life can be, or how your brain can think in life...

Rabbi Shapiro's use of cultivation and fertility metaphors in this case are particularly interesting, because Colleen Macklin (Macklin, 2017) has emphasized distinctions between Stardew Valley (Sickhead Games, 2016) and Minecraft. In her keynote at Games for Change, Macklin observes that in Stardew Valley, the ethos is one of community, cultivation, and sharing. Minecraft she characterizes as having an ideology of "let's exploit the land and steal stuff from the villagers who are like sheep." Macklin acknowledges positive learning that happens in Minecraft, but emphasizes the authorial structuring of rules that can be read to have their own ideology.

While Macklin hints at the possibilities of players using a video game for alternative interpretations and actions, she does not discuss considerations of reception studies such as the work of Stuart Hall as interpreted for digital media more recently by Adrienne Shaw (2017). Reception studies would emphasize how the video game is interpreted, used, and negotiated by the players or fans or spectators. Shaw emphasizes the affordances, that which the medium allows the player to do, of the given medium. She stresses how interactivity permits an additional layer because the player, dependent upon and limited by the affordances provided, participates in the creation of the play experience. I argue that Minecraft is a good example of this because it is a design tool. While bounded by the shape of the blocks and the mechanics of the game (mining and crafting), Minecraft allows Joel to recast play for a religious purpose. In this way, Shapiro, the farmer who played with Legos, sees his own biography of cultivation and fertile creativity in 
the Minecraft play space and in what it could afford to his student. For Shapiro, Minecraft, if used well, could actually be more like Stardew Valley.

Shapiro goes on to describe his perception of the kind of learning happening through Joel's Minecraft designing:

I think these things [Minecraft, Legos] produce the kind of learning that when you ask somebody what they learned, they shrug and say "I don't know, I just built this thing. This was fun." But yet, down the road, you see that they are clearly thinking, behaving, and cognitively acting in ways that other people are not. So that kind of scaffolding of the mind is what I think those things teach without teaching facts, without teaching knowledge [for] regurgitating. I really think it is cultivating the scaffolding of the mind or that skeletal kind of thought process of the mind that you can't notice until you look back and become really introspective and think, "Well where did this come from? Why am I different in this way from other people?"

Here, Shapiro uses terms that could be construed as referring to specific educational concepts, yet it appears that he has applied his own frameworks to them. Shapiro holds a masters of education, though he uses scaffolding in a more literal sense here than the term of art in education. "Scaffolding" (Wood \& Middleton, 1975; Wood, Bruner, \& Ross, 1986) in education theory typically refers to Lev Vygotsky's Zone of Proximal Development (see Vygotsky’s Mind in Society, 1978), and how a teacher provides bridging between what the learner can handle on their own and when the learner requires assistance. Here, Shapiro uses the term literally, referring to a skeleton, describing the kind of learning that happens through making as both a) foundational (as a skeleton is foundational to a body) and b) unconscious, unreflected, or background process. This argument fits squarely into the learning theory of constructionists: that 
learners learn by making and building and in doing so, they construct mental models. Shapiro says that he has neither studied, nor read, nor even heard of the constructionists before our conversation. Yet his own story provides yet another case supporting those learning scientists' propositions and the results of their decades of research. It seems that Shapiro's constructionist outlook derives more from his upbringing on the farm and in play with Legos than from formal training in graduate school.

When asked about the relationship between Joel's creative building in Minecraft and connections to religious experience or expression, Shapiro comments,

That is a piece that is not hard to translate, because if you look at what kids construct, what they value is almost always present in what they have constructed, and so once you have a set of values or something that is illustrative of values, it's just a matter of translation until you get that into the world or the realm of religion or spirituality-because religion and spirituality make order and ritualize values and beliefs, and as long as you are able to find that [values and beliefs] in what the kid has made, then you can start to translate that into, or perhaps, you yourself, can then illustrate what they are valuing is already in the religion or vice versa and start forging connections that way.

Shapiro provides an example:

In his Minecraft build there was a prison and a good deal of treasure or gold... And I could see a direct dialogue to his experience in motivation in his life. Things needed to be visceral and applicable and sensible for him. So, [if] you don't do x then you get shut down, or closed off from the things you want to do-there's that prison. [If] you do do $x$, and you do it well, you get the [food], the gaming console, or computer, and there [in his Minecraft] is 
the golden cup [the goblet that Joseph accuses the brothers of stealing in the Torah portion]. And I think that cognitive piece that works for him, that he then began to place value in, because, "Okay, these are the things I need to do to get this" [referring to external reward incentives] ... all of that was visibly present in what he did, and then that becomes fodder for me, as kind of the shepherd of this process, to then ask questions that kind of speak towards that, that tease it out in different ways... because if those are the terms in which he is thinking, then you can ask questions that are in those same terms about the Torah portion... like, "Why do you think the brothers are into this?" or "Why do you think Joseph would do that?"

Here, Shapiro uses the artifact Joel is creating to more deeply understand how to lead and challenge Joel. The Minecraft designs not only provide Joel a venue for expression and creativity, but also a textual exegesis and a text artifact itself that Shapiro can then use for deepening Joel's inquiry of the Torah. Text study is often core to Jewish spiritual and religious practice (see Gottlieb, 2015a).

In the case of Joel's bar mitzvah, the negotiation of Minecraft appears to be deeply impacted by the biography of Rabbi Shapiro. Shapiro is able to see his own childhood experiences with Legos and learning on the farm. Minecraft fits into Shapiro's constructionist ethic (though he did not refer to "constructionism" himself). Shapiro's "geography" reflects the Jewish position of the teacher and student being "with" one another at the same place, and Shapiro's "language" of making fits within the design aspects of the game that have made Minecraft popular in games and learning circles (see https://education.minecraft.net/ and http://minecraftteacher.tumblr.com/). 
Differentiated Instruction: Accessibility and Inclusion

To contextualize the Minecraft Bar Mitzvah, it is important to explore some conceptions about differentiated instruction and also accessibility and inclusion in contemporary progressive Jewish circles and institutions. I use the term "progressive Judaism" to describe non-Orthodox movements: Reform, Conservative, and Reconstructionist, along with Renewal Judaism, which has long seen itself as "not a movement," and with post-denominational Jews who affiliate with other progressive Jews. ${ }^{4}$ In some ways, "Open Orthodoxy" is seen as progressive in many of its approaches. A 2013 Pew study (Lugo, Cooperman, \& Smith, 2013) claims 1.5 million Reform Jews across approximately 900 synagogues. Rabbi Shapiro and his senior colleague, Rabbi Bernstein, are both Reform rabbis who trained at the Hebrew Union College and are working in a Reform-affiliated congregation, a member of the Union for Reform Judaism. Rabbi Shapiro's notion of reaching the learner or Jewish person "where they are" is very much a part of Jewish education in progressive settings. This is not only the case regarding differentiated instruction, but also regarding kiruv, or outreach, and contemporary conscious efforts of inclusion. I will address each of these in turn.

Contemporary differentiated instruction in Judaism is informed by a tradition reaching back centuries. While the Torah itself has examples of different kinds of instruction for different

4 Post-denominational Judaism in North America in recent years is likely best understood through the lens of the rabbinical school at Hebrew College as distinct from Hebrew Union College (Reform). Hebrew College is not connected to a particular denomination, though its students and graduates tend to hold similar level positions in Jewish institutions across the movement spectrum as other groups of progressive Jews. 
people, perhaps the most famous Jewish text regarding differentiated instruction is the Passover Haggadah. The earliest manuscript of the Haggadah dates back to the 8th century and was found in the Cairo Genizah (Gilad, 2014). In "the four sons" section of the Haggadah, the text, drawing from Exodus, Deuteronomy, and other sources, provides four sons of different attitude and temperament, and explains how the mode of teaching the story of the Exodus should differ for each. Jewish educators today look back and interpret this passage, understanding it to reflect differentiated instruction. A widely used Haggadah in progressive Jewish circles in recent decades is A Different Night, which reads, "The Haggadah offers us educational advice about intergenerational storytelling. The midrash of the Four Children invites us to distinguish different character types and to suggest different approaches to our offspring” (Dishon \& Zion, 1997, p. $56)$.

Regarding accessibility and inclusion, Reform Judaism presents itself institutionally, and as a movement, as having an ever wider and more expansive "tent." While this idea of an open tent refers back to Abraham and Sarah in the Hebrew Bible, this notion was elevated in the address of President Rabbi Rick Jacobs at the 2017 Union for Reform Judaism's (URJ) Biennial. In the speech, Jacobs (2017) emphasizes the notion of "Audacious Hospitality," which on the Union's website is described as follows:

As part of the URJ's 2020 vision, Audacious Hospitality is the focused effort to embrace our diversity and reach out to those currently not engaged in Jewish life. The URJ believes that everyone can feel at home in Jewish community - and that Judaism must meet people where they are today to thrive tomorrow. As a movement, we stand for a Judaism that is inclusive and open-we believe that there is more than one authentic way to be Jewish. Audacious Hospitality is a transformative spiritual practice rooted in the belief that we will be a 
stronger, more vibrant Jewish community when we fully welcome and incorporate the diversity that is the reality of modern Jewish life (URJ, 2017).

Audacious Hospitality includes strategic initiatives including a Transgender Inclusion Active Learning Network and a Disabilities Inclusion Learning Center, “offering Reform professionals resources to develop additional skills, strategies and understanding to make full participation of people with disabilities in congregational and communal life possible" (URJ, 2017). But these concerns are not new, they have only come front and center more recently. The Reform movement has long been trending to wider inclusion. In 1972 the Reform movement ordained Sally Preisand, the first woman Rabbi in North America. In 1983 the Reform movement published its Resolution on Patrilineal Descent with references back to the 1961 rabbi's manual — making it clear the Reform movement considers a person whose father was Jewish to be Jewish (as distinct from solely matrilineal descent).

A further rising consciousness of and effort to expand inclusion and accessibility seems to be happening in progressive Jewish circles over the last decade or so. In 2007 Rabbi Judith Abrams examined Reform Responsa (roughly, interpretations of Jewish law) regarding Persons with Disabilities (Abrams, 2007). The story of a Reconstructionist family's son with Down Syndrome having a bar mitzvah was memorialized and shared in a popular documentary, Praying with Lior, (Trachtman, 2008 (see Lederman, 2008)). By January 2019, the URJ had published an article with guidance for the upcoming February series of events: "11 Ways to Celebrate Jewish Disability Awareness, Acceptance, and Inclusion Month in Your Synagogue" (Menscher, 2019).

The longstanding push to "widen the tent" and the growing movement for greater inclusion and accessibility are both important contexts for considering the Minecraft Bar 
Mitzvah, especially regarding the clergy's understanding of their mission and how new media may or may not be resonant and in line with that mission.

Mission Alignment

Rabbis Shapiro and Bernstein understood the use of Minecraft in very specific frames. For Shapiro, the key question was whether it was the language of the learner, and specifically, one that would unlock an experience otherwise not open. For Bernstein, the evaluation of Minecraft was dependent on whether the use of the video game fit a service missionspecifically, to help be a more inclusive community for those with differences. It so happens that even the written mission statement of the synagogue specifically called out celebrating the diversity of the Jewish community.

Bernstein, the senior rabbi of the synagogue, was explicit on this topic, telling the story of his own discomfort and sometimes concern with how involved his own son was with playing Minecraft. He drew a marked distinction between his son's playing and the case of use of Minecraft in Joel's bar mitzvah—because in the case of Joel's bar mitzvah, Minecraft design and play, as guided by Rabbi Shapiro, was about a way to be more inclusive as a synagogue for someone who was special needs (neurodiversity). The negotiation towards the end of inclusivity was the key distinction. It was not easy or typical to construct a makeshift screen and rig the chapel for a Minecraft sermon. And this effort was years prior to "Audacious Hospitality" initiatives.

I think we went way beyond and I felt very good about that.... This is a kid with a special need and finding a solution to allow them to function... The limit is always are we supporting the mission, the mission of what we are doing, right? Are we helping to create meaningful, spiritual, lifecycle observance, and does it speak to the kid, does it speak to the 
family, is it achieving its goal. In this case, the answer was check, check, check every box.... And it was beautiful. It was absolutely remarkably and beautiful. I am so proud of [Rabbi Shapiro] and so proud of [Joel] and his family. It was really spectacular.

The negotiation and validation of the video game is understood in the context of the synagogue's mission, what are longstanding traditions of differentiated instruction and historical and growing trends of tent-widening (today under the auspices of "inclusion and accessibility" and even "Audacious Hospitality"). Jewish tradition can be understood to have a long history of understanding the need for differentiated instruction, and the Reform and progressive approaches to Jewish life are resonant with broadening inclusion and access. Even when Rabbi Bernstein was uncomfortable about Minecraft play taking up many hours of his own son's time, when it becomes obvious that it could be a path for a person with special needs to access a religious lifecycle ritual, it is clear to him that his team should be incorporating new media, and specifically, the video game, Minecraft. The process of accepting Minecraft in a validated framework led to innovation.

Conclusion

The processes of negotiation, acceptance, and validation of Minecraft into the heart of the bar mitzvah ritual is better understood in a thicker context than the content of the Minecraft program itself, its design, or the function of the media and technology in the religious ceremony. The ritual extends beyond the bimah and into the learning sessions, the preparations, and more broadly, the factors exerting influence on the innovation. Shapiro's narrative provides context of a rabbi-educator who is particularly attuned to his own biography, his own philosophy of learning, and able to articulate that philosophy regarding how to best reach young learners and allow them to harness their own "language." Bernstein's narrative highlights impinging 
institutional factors that bound and permit the negotiation. Bringing together the long-standing traditions regarding teaching and learners differently in Judaism, and understanding the institutional and movement trends regarding expanding the tent and providing access and inclusion as broadly as possible, the innovation of bringing Minecraft to the bimah, while by no reports easy, was sanctioned at a deep level — at the level of the mission of the synagogue and the personal educational and spiritual mission of the clergy.

The direct connections between narrative, biography, and pedagogy in this case suggest that for those who guide, gatekeep, and may have the opportunity and desire to innovate, determining the relationship to media and modes of learning in the personal stories of clergyeducators could provide new insight into the heart of processes of negotiation. Likewise, situating the mission orientation of the related institutions may allow better understanding of how and when mission outweighs perceived threats of the new media, especially in Jewish settings that do not bar electronics on Shabbat. Conservative and Orthodox congregations mostly disallow electronics on Shabbat, due to their style of observance of the weekly holiday, and bnai mitzvot are often celebrated on Shabbat. For Reform synagogues who openly use electronics on Shabbat, the key limits to new media innovation, at least in this case, come back to congregational mission and movement/institutional priorities followed by practical and logistical concerns.

This is the first case that I have come across of the use of a video game in a bar mitzvah ceremony. Will the use of video games in Judaism be more common, or remain the rare occurrence? In 2012, about a year before the Minecraft Bar Mitzvah, Exeter Cathedral in Devon England (Cathedral...FamilyGamerTV, 2012) incorporated the meditative game Flower (That Game Company, 2009) into a worship service. In late 2018 and 2019 Microsoft premiered ads 
for their new adaptive Xbox controller, including one during the 2019 Super Bowl (Microsoft, 2019). One nine year old with a with a rare genetic disorder called Escobar Syndrome (Schlosser, 2018) says in the Super Bowl ad, "No matter how your body is, or fast you are...you can play...it's a really good thing to have in this world" (Microsoft, 2019). Perhaps with the increasing interest in improved accessibility for video games and computing, paired with similar concerns in progressive Judaism, new media technologies will also grow even more fully into the space of inclusion. As teachers and clergy continue to aim to meet learners "where they are," a deeper understanding of the stories, the negotiation narratives, and the biographies of those clergy will be crucial for scholars seeking insights into how religious communities negotiate practices with new media.

References

Abrams, R. J. Z. (2007). Reform Responsa Concerning Persons with Disabilities. Journal of Religion, Disability \& Health, 10(3-4), 53-72.

Ackermann, E. (2001). Piaget's Constructivism, Papert's Constructionism: What's the Difference? Future of Learning Group Publication, 5(3), 438.

Aron, I. (2010). Supplementary Schooling and the Law of Unanticipated Consequences: A Review Essay of Stuart Schoenfeld's "Folk Judaism, Elite Judaism and the Role of Bar Mitzvah in the Development of the Synagogue and Jewish School in America." Journal of Jewish Education, 76(4), 315-333. doi: 10.1080/15244113.2010.518312.

Bellwether Events and Deb Lindsey, (n.d.). Minecraft Bar Mitzvah. Ideas and Plans for a Minecraft Themed Bar Mitzvah (birthday party). Retrieved from https://www. pinterest.com/bellwetherevent/minecraft-bar-mitzvah/.

Bellwether Events. (2014, March 18). Wyatt's Minecraft Bar Mitzvah Party. Retrieved from https://bellwetherevents.com/uncategorized/minecraft-theme- bar-mitzvah-party/.

Campbell, H. (2010). When Religion Meets New Media. New York, NY: Routledge. 
Campbell, H. A. (Ed.). (2015). Digital Judaism: Jewish Negotiations with Digital Media and Culture. New York, NY: Routledge.

Cathedral Service Using PlayStation 3 Game Flower (FGTV 2.4). (2012). FamilyGamerTV. Retrieved from https://www.youtube.com/watch?v=wREUXBf6fho.

Clandinin, D. J. \& Connelly, F. M. (2000). Narrative Inquiry: Experience and Story in Qualitative Research. San Francisco, CA: Jossey-Bass.

Creswell, J. W. (2007). Qualitative Inquiry and Research Design: Choosing among Five Approaches (2nd ed.). Thousand Oaks, CA: SAGE Publications, Inc.

Czarniawska, B. (2004). Narratives in Social Science Research. London: SAGE Publications Ltd.

Dishon, D. \& Zion, N. (1997). A Different Night, The Family Participation Haggadah (New Storytellers' ed.). Jerusalem: Shalom Hartman Inst.

Flower [Computer software]. (2009). Los Angeles, CA: Thatgamecompany, Ltd.

Gilad, E. (2014, April 14). Who Wrote the Passover Haggadah? Haarretz. Retrieved from https://www.haaretz.com/jewish/who-wrote-the-haggadah-1.5245069.

Gottlieb, O. (2013). You Can't Wrap Herring in an iPad: Digitization of Sacred Jewish Books, the Stripping of Embodied Ritual, and Implications for Jewish Education. CCAR Journal: The Reform Jewish Quarterly, Spring, 130-141.

Gottlieb, O. (2015a). Jewish Games for Learning: Renewing Heritage Traditions in the Digital Age. In H. Campbell (Ed.), Digital Judaism: Jewish Negotiations with Digital Media and Culture (pp. 91-109). Routledge. http://www.routledge.com/books/ details/9780415736244/.

Gottlieb, O. (2015b). Mobile, Location-Based Game Design for Teaching Jewish History: A Design-Based Research Study. (Doctoral Dissertation) New York University. Retrieved from Proquest.

Harel, I. \& Papert, S. (1991). Constructionism. New York, NY: Ablex Publishing.

Hoover, S. (1993). What Do We Do about the Media? Conrad Grebel Review, 11, 97-107.

Jacobs, R. R. (2017, December). A River Flows from Eden: Rabbi Rick Jacobs'Address to the URJ Biennial. Presented at the URJ Biennial, Boston, MA. Retrieved from https:// urj.org/blog/river-flows-eden-rabbi-rick-jacobs-address-urj-biennial. 
Kafai, Y. B. and Resnick, M. (2012). Constructionism in Practice: Designing, Thinking, and Learning in a Digital World. New York, NY: Routledge.

Lederman, F. (2008). "Praying with Lior:” Toward an Inclusive Reimagining of Disability. Philadelphia, PA: Taylor \& Francis.

Lugo, L., Cooperman, A., and Smith, G. A. (2013). Pew Research Center Survey of US Jews: A Portrait of Jewish Americans. Pew Forum. Retrieved from https://www. pewforum.org/2013/10/01/jewish-american-beliefs-attitudes-culture-survey/.

Macklin, C. (2017). Keynote-Gaming the System: The Political Potential of Play with Colleen Macklin. Presented at the Games for Change 2017, New York City. Retrieved from https://www.youtube.com/watch?v=Eh_uZPb4b3M\&t=17s.

Maimonides, M. (2010). Mishneh Torah: Sefer Hamadah-Book of Knowledge. In Touger R. E. (Ed.), Mishneh Torah Series. Brooklyn, NY: Moznaim Pub Corp.

Menscher, R. E. H. (2019, January 18). 11 Ways to Celebrate Jewish Disability. Retrieved from https://urj.org/blog/11-ways-celebrate-jewish-disability-awareness-acceptance- and-inclusionmonth-your-synagogue.

Merriam, S. B. (1995). What Can You Tell from an $\mathrm{N}$ of 1?: Issues of Validity and Reliability in Qualitative Research. PAACE Journal of Lifelong Learning, 4, 51-60.

Meyer, B. (2009). Aesthetic Formations: Media, Religion, and the Senses. New York, NY: Palgrave Macmillan.

Microsoft. (2019). We All Win (Extended Version). Retrieved from https://www.youtube. com/watch?time_continue $=73 \& v=\_Y I S T z p L X C Y$.

Minecraft [Computer software]. (2011). Stockholm, SE: Mojang.

Papert, S. A. (1993). Mindstorms: Children, Computers, and Powerful Ideas (2nd ed.). New York, NY: Basic Books.

Schlosser, K. (2018, November). Microsoft Holiday Ad Captures Joy of Video Games and Inclusion as Boy uses Xbox Adaptive Controller. GeekWire. Retrieved from https://www.geekwire.com/2018/microsoft-holiday-ad-captures-joy-video-gamesinclusionboy-uses-xbox-adaptive-controller/. 
Schoenfeld, S. (1987). Folk Judaism, Elite Judaism and the Role of Bar Mitzvah in the Development of the Synagogue and Jewish school in America. Contemporary Jewry, 9(1), 67.

Shaw, A. (2017). Encoding and Decoding Affordances: Stuart Hall and Interactive Media Technologies. Media, Culture \& Society, 39(4), 592-602. doi: 10.1177/0163443717692741. Stardew Valley [Computer software]. (2016). Dallas, TX: Sickhead Games.

Trachtman, I. (2008). Praying with Lior [DVD]. New York, NY: First Run Features. URJ. (2017). Audacious Hospitality. Retrieved from https://urj.org/tags/audacious- hospitality (last accessed 2019).

Vygotsky, L. S. (1978). Mind in Society: The Development of Higher Psychological Processes (14th ed.). Cambridge, MA: Harvard University Press.

Wood, D. \& Middleton, D. (1975). A Study of Assisted Problem-Solving. British Journal of Psychology, 66(2), 181-191.

Wood, D., Bruner, J. S. \& Ross, G. (1976). The Role of Tutoring in Problem Solving. Journal of Child Psychology and Psychiatry, 17(2), 89-100. 